\title{
NILAI-NILAI KEMANUSIAAN DALAM CERITA ANAK MINANGKABAU
}

\author{
Satya Gayatri, Ria Ariany, Ratni Prima Lita, dan Isramirawati \\ Universitas Andalas, Padang, Indonesia. \\ Email: satyagayatri@hum.unand.ac.id
}

\begin{abstract}
This article describes human values in oral stories for children from Minangkabau. This issue was raised because many traditional stories are neglected and underappreciated. The stories analyzed were 30 stories by considering the message of the story. The oral story data was obtained by recording and transcribing. Analyzing the story is done by reading it many times so that the news is received. The study results found that the story's message was to respect parents, especially mothers, the value of honesty was carried out under any conditions, to maintain a friendship in all forms of activity, and to restrain emotions in all actions.
\end{abstract}

Keywords: Humanitarian Values, Oral Stories, Minangkabau Children's Stories, and Humanitarian Values.

\section{PENDAHULUAN}

Awal abad ke-20, para intelektual dan pemimpin Indonesia banyak berasal dari Minangkabau sehingga membawa Indonesia lepas dari penjajahan (Chaniago, 2010). Mereka dari kalangan birokrat, alim ulama, pemikir, sastrawan, dan penulis yang muncul di bagian terdepan serta memainkan peranan berarti dalam proses pembentukan bangsa, pergerakan nasional, pergerakan Islam, serta penentu sastra dan budaya Indonesia (Hadler, 2010: 2). Karakter kepemimpinan itu datang dari latar belakang budaya yang didapatnya sejak kecil. Kehidupan waktu kecil merupakan modal bagi mereka menjadi pemimpin yang terkemuka. Keadaan itu membuktikan bahwa nilai-nilai tradisional Minangkabau seperti nasehat, nilai kebijaksanaan, kearifan dalam bentuk ajaran membuat mereka berkepribadian yang kuat. Semua nilainilai dalam budaya Minangkabau itu dituangkan dalam bentuk lisan melalui ungkapan tradisional (Hasanuddin, 2006: 140), termasuk juga hukum, falsafah, dan peraturan-peraturan berbentuk lisan (Anwar, 1995). Waktu itu, tradisi lisan merupakan alat berkomunikasi dan domain yang bisa dilihat dari berbagai ilmu (Wilson,-2014).

Tradisi lisan dalam masyarakat Minangkabau telah diperkenalkan dan disampaikan sejak dari kecil, terutama terhadap anak laki-laki. Anak laki-laki jika sudah berumur 10 tahun tidak "diizinkan" lagi tidur di rumah gadang. Mereka menerima pelajaran, bergaul, dan beradaptasi dengan kehidupan di luar keluarga dan rumah gadangnya. Mereka akan bergabung dan tidur di surau bersama dengan laki-laki yang berasal dari kaum yang sama (Azra, 2003; Hadler, 2010). Di surau, mereka belajar persoalan agama seperti belajar sholat, mengaji, belajar persoalan adat, hidup bermasyarakat (Naim, 1985). Setelah anak-anak selesai belajar dan menjelang tidur mereka mendengarkan cerita-cerita (Hadler, 
2010: 193). Cerita yang disampaikan dengan mendongeng atau kontak sosial menjalin kedekatan emosi dan rasa gembira (Jirata, 2013).

Anak perempuan mendengarkan cerita dari nenek atau saudara ibu perempuan yang belum menikah. Semua orang ini tidur di rumah gadang yang sama. Dengan bercerita orang tua dan karib kerabat menyampaikan pendidikan dan pesan yang positif kepada anak-anaknya sebelum tidur (Gayatri, 2020).

Tradisi lisan merupakan salah satu bentuk folklor yang juga digunakan untuk menyampaikan nilai-nilai seperti di atas. Tradisi lisan sarat dengan pendidikan, maka bagi peneliti folklor di Amerika, tradisi bukan hanya kelompok masyarakat, tetapi juga meliputi norma, sistem nilai-nilai estetika dan budaya etnis, agama dan kepercayaan yang digunakan oleh rakyat setempat (Sukatman, 2009). Tradisi merupakan aktifitas kehidupan manusia yang berlangsung berulang-ulang. Tradisi dan pendidikan karakter dapat dilakukan melalui folklor biasanya lewat folklor lisan (Endraswara, 2013; 7). Folklor lisan salah satunya adalah cerita anak. Namun, cerita lisan ini telah banyak tidak dikenal oleh anak-anak saat ini (Mursini, 2011).

Anak-anak yang telah mampu membaca bisa menikmati cerita lewat tulisan dan salah satu menyebabkan anak-anak jauh dari tradisi lisan. Akhirnya, tradisi bercerita mengalami pergeseran dari oral ke tulisan. Keadaan ini membuat mereka mengetahui cerita tidak lagi lewat lisan tetapi melalui bacaan (Sugihastuti, 2013: 6). Tradisi bercerita yang awalnya dilakukan secara lisan mengalami perubahan seiring dengan ditemukannya mesin cetak. Tradisi lisan berangsur mengalami erosi dan akibatnya kontak sosial antara anak dengan orang tua atau sesama semakin hilang (Jirata, 2013, Sugihastuti, 2013: 7 dan 31).

Cerita lisan salah satu tradisi yang mengandalkan performan lisan yang kuat, indah, memiliki nilai artistik dan kemanusiaan yang tinggi (Ong. 2013: 19; Ahimsa-Putra, 2003). Selain sebagai alat penghibur, pengisi waktu senggang, serta penyalur perasaan bagi penutur dan pendengarnya, cerita lisan juga berfungsi cerminan sikap, pandangan dan anganangan kelompok, alat pendidik bagi anakanak, alat pengesahan pranata dan lembaga kebudayaan serta pemeliharaan norma masyarakat (Danadjaja, 1984; Fitrah, 2012). Cerita lisan berasal dari berbagai cerita rakyat atau mitos yang ada di masyarakat dan tidak dituliskan serta mengandung keindahan (Ahimsa-Putra, 2003: 78).

Selain nilai-nilai yang terdapat dalam cerita lisan, tradisi bercerita bagi seorang anak ternyata cukup efektif mengurangi perasaan stress dan gangguan tidurnya (Musfiroh, 2008). Bagi anak-anak di usia dini dengan cara mendongeng terjalin komunikasi yang efektif antara anak dengan pengasuhnya serta mampu menurunkan detak jantung anak tersebut. Mendongeng yang diberikan oleh pengasuh dapat meningkatkan komunikasi, konsentrasi, dan media pengajaran yang efektif. Walaupun dongeng hanya diberikan dalam waktu lebih kurang 15 menit, namun hasilnya cukup efektif untuk perkembangan kognitif dan psikologi anak asuh (Khoiriyah, 2015).

Tradisi bercerita bagi anak-anak di Minangkabau saat ini sudah hampir hilang. Banyak anak-anak tidak kenal lagi dengan cerita tradisional yang ada di daerahnya. Jika mereka menikmati cerita dapat dengan cepat diaksesnya melalui media seperti televisi, film kartun, internet dan lain-lain. Kegiatan bercerita seperti ini dimulai sejak masuknya televisi ke daerah mereka (Bunanta, 1998: 28; Udasmoro, 2012: 2) sehingga interaksi sosial seperti antara orang tua dengan anak-anak semakin berkurang (Tulius, 2013). Meskipun demikian, sekitar dua puluh tahun yang lalu tepatnya sebelum 
internet ditemukan maka tradisi bercerita masih hidup dalam masyarakat. Namun, sekarang internet secara fundamental telah mengubah dunia ke dalam kehidupan sehari-hari. Seharusnya kemajuan ini dimanfaatkan seperti di beberapa negara yang mendokumentasikan tradisi lisan secara profesional (Blank, 2009).

Cerita lisan anak di Minangkabau tidak banyak dikenal dan telah dituliskan juga minim. Keadaan ini sudah berlangsung lama (Gayatri, 2010), seperti majalah untuk anakanak yang terbit di awal tahun 1900-an juga tidak memuat cerita anak (Sunarti, 2013). Penelitian terhadap nilai-nilai dalam cerita anak telah banyak dilakukan sesuai dengan tujuan dari cerita anak untuk menyampaikan nilai atau pendidikan kepada anak-anak. Zakaria (2013) mengungkapkan adanya nilai-nilai murni yang terdapat dalam cerita rakyat " $\mathrm{Si}$ Luncai" dari Malaysia. Nilai-nilai murni itu adalah nilai-nilai di kalangan anak-anak yang berkaitan dengan perlakuan baik, peradaban dan tata susila individu untuk berhubungan dengan sesama manusia, alam, dan Tuhan. Dalam cerita "Si Luncai" adanya nilai dan perwatakan pemimpin di Malaysia pada saat ini dan cerita ini mengandung pengajaran, pendidikan, dan dapat jadikan sindiran terhadap kalangan politik pada waktu itu. Cerita anak-anak bisa juga dihadirkan dalam bentuk gambar seperti komik (Nurgiyantoro, 2010).

Dengan membaca cerita anak berbentuk gambar akan memperlihatkan cara tokoh berinteraksi, bernegosiasi dengan sesama tokoh atau dengan lingkungan sehingga bercerita akan terjalin rasa sosial. Kehidupan dan kebersamaan sosial pada anak-anak telah mulai dan dibentuk ketika mereka berusia 3-5 tahun. Pada usia 1012 tahun ini mulai timbul dan semakin tinggi tingkat kepeduliannya. Oleh sebab itu, pada umur ini anak-anak disugguhkan cerita yang menanamkan kepekaan sosial. Kepekaan sosial, pertumbuhan rasa etis, dan religius bisa dilakukan melalui tingkah laku orang tua serta lewat tokoh-tokoh yang ada dalam cerita yang menyampaikan. Selanjutnya, nilai pendidikan dalam cerita bisa terlihat dalam bentuk eksplorasi dan penemuan, perkembangan bahasa, pengembangan nilai keindahan, penanaman wawasan multikultural, menanamkan kebiasaan membaca (Nurgiyantoro, 2010: 40-47). Melalui cerita dapat memberikan nilai yang positif bagi seorang anak dengan mengamati tingkah laku, sikap, dan pandangan yang dilakukan oleh tokoh (Nurgiyantoro, 1998; Fitrah, 2012).

\section{METODE PENELITIAN}

Cerita diambil dari cerita lisan. Cerita lisan ditranskripsikan dan bagian cerita yang dikutip diterjemahkan ke dalam Bahasa Indonesia. Metode terjemahan menggunakan terjemahan komunikatif (communicative translation) sesuai dengan konteks cerita bukan terjemahan secara kata perkata supaya pembaca memahami konteks yang disampaikan (Hartono, 2017). Data primer merupakan cerita yang menyampaikan nilai-nilai bersifat universal di masyarakat.

Menganalisis data dilakukan dengan membaca cerita secara berulang. Membaca seperti ini untuk membedakan nilai-nilai yang dari cerita. Pesan itu dapat ditarik dengan menentukan tokoh, tindakan, sikap dan nasari yang disampaikan. Dari semua elemen yang ada dalam cerita tersebut dilakukan interpretasi agar pesan yang disampaikan ditemukan.

\section{HASIL DAN PEMBAHASAN \\ Hasil}

Kajian sastra dapat dibedakan dua bentuk. Pertama, berasal dari tradisi lisan dan kemudian ditranskripsikan ke bentuk tertulis dan dicetak (Sarumpaet, 2010). Materinya diangkat dari cerita tradisional yang beredar secara 
lisan, seperti dongeng, legenda, hikayat, mitos, cerita binatang, dan cerita lainnya. Kedua, sastra anak yang sengaja ditulis, diciptakan untuk dikomsumsi anak-anak. Dari segi isinya, cerita ini sesuai dengan minat, intelektual, dan emosi anak-anak. Kedua bentuk karya sastra ini sesuai dengan hakikat sastra secara umum yang bertujuan dan berfungsi utile et dulce (Sikana, 2007, Musfiroh, 2008; Mursini, 2011). Dalam dunia pendidikan, sastra merupakan alat pengajaran yang kuat untuk menanamkan karakter, membantu anak-anak menyerap, dan mengembangkan karakter yang kuat (Almerico, 2004).

Cerita dianalisis untuk anak-anak yang berusia 6-12 tahun (Sastriyani, 2006: 2). Konsep masa kanak-kanak bervariasi dari satu budaya dengan budaya lain. Dunia pendidikan di Amerika misalnya mendefinisikan anak sekolah dari TK sampai kelas 12 (Tucker, 2008: 21). Cerita disampaikan kepada anak yang belum bisa membaca di bawah bimbingan dan arah orang tua. Namun, jika cerita itu ditulis maka penulisannya bisa saja dilaksanakan oleh orang dewasa. Cerita anak seperti ini merupakan karya yang khas dari dunia anak, dibaca untuk anak, dan dibimbing oleh orang tua (Sarumpaet, 2010: 2). Tokoh dalam cerita anak digambarkan secara simbolik dan mereka akan mudah mengidentifikasi tokoh mana yang baik dan buruk. Tokoh dalam cerita itu lazim menampilkan stereotip tertentu, gaya bahasanya bersifat sederhana dan tidak detil ceritanya, serta tidak membingungkan (Bunanta, 1998: 14-15). Demikian juga dengan tema dari tidak bervariasi, sangat dominan unsur didaktiknya, serta bersifat monoton (Sastriyani, $2006: 10$ ).

Sastra anak bertumpu sebagai pedoman dalam kehidupan sehari-hari (Fitriana, 2013). Oleh karena itu, sastra anak bermanfaat untuk 1) membantu membentuk pribadi dan moral anak-anak, 2) menyalurkan kebutuhan imajinasi dan fantasi, 3) memacu kemampuan verbal, 4) merangsang minat menulis, 5) merangsang minat baca, dan 6) membuka cakrawala pengetahuan anak (Musfiroh, 2008: 81- 100). Di waktu menceritakan atau membaca sebuah cerita misalnya, emosi anak sedang bergerak yang dipengaruhi oleh tema dan masalah cerita. Anak-anak membutuhkan cerita karena memerlukan pengalaman bathin untuk memperkaya bathin dan emosinya. Melalui cerita anak-anak diharapkan memperoleh pengalaman bathin dan segala kemungkinan untuk melengkapi psikologi mereka (Sugihastuti, 2013: 39-41).

\section{Pembahasan}

Cerita lisan tidak mengutamakan fakta dan kebenaran tetapi yang dipentingkan supaya cerita dapat memberikan hiburan dan pengajaran (Sikana, 2007:17-18), walaupun ada cerita yang tidak mungkin terjadi sesuai dengan pemikiran dan nalar manusia. Fakta cerita itu terjadi pada teks persuasif yaitu cerita dengan tokoh binatang. Meskipun demikian, cerita fabel merupakan cerita yang bersifat mengajarkan sesuatu hal, menyakinkan, menimbulkan humor, mengharukan, dan memberikan informasi untuk anak-anak (Sugihastuti, 2013: 25). Di samping itu, cerita anak memberikan prioritas kepada penerima, pembaca, atau pendengar yang disesuaikan dengan pemikiran anak-anak dan membuat mereka terhibur. Pendidikan karakter tidak hanya diajarkan di sekolah, tetapi justru disampaikan pada anak-anak sedini mungkin waktu otak mereka masih 'kosong' (Ratna, 2014). Oleh sebab itu, cerita corak pendidikan layak diberikan pada anak-anak sebelum mereka berumur 8 tahun atau sekitar kelas dua sekolah dasar. Namun, cerita bukan hanya berfungsi sebagai hiburan tetapi juga bermanfaat bagi perkembangan 
anak termasuk perkembangan holistik anak, emosional, moral, bahasa, dan sosial. Cerita dapat juga mengajarkan anak akan rasa cinta, benci, marah, sedih, gembira dll. Dari sebuah cerita lisan. anak-anak dapat mengembangkan kemampuannya bernarasi serta menumbuhkan minat untuk membaca (Bunanta, 1998: 52; Sugihastuti, 2013).

Sebelum menjelaskan nilai, pesan, edukasi, dan persoalan positif dari cerita anak, terlebih dahulu ditampilkan judul-judul cerita anak Minangkabau yang telah peneliti kumpulkan. Cerita yang telah dikumpulkan sebanyak 28 cerita. Judul cerita sama dengan judul yang disampaikan oleh informan. Pesan cerita dimuat di tabel ditampilkan secara garis besar dan analisis dilakukan di bawahnya.

Tabel 1 Cerita Anak Minangkabau dan Pesannya

\begin{tabular}{lll}
\hline $\begin{array}{l}\text { No } \\
\text { paikan }\end{array}$ & $\begin{array}{l}\text { Pesan yang Disam- } \\
\text { panak harus santun }\end{array}$ & Si Buncik, Sapan \\
& Anada orang tua & Mandidiah, Bancah \\
& terutama terhadap & Birunguik, Batu \\
& ibu & Bangkai, Batu \\
& & Balacan, Awang \\
& & Tingkuluak, Aia \\
& & Manggaloggak, \\
& & Boncah Tangkuluak, \\
& & Tobek si Ombie, Batu \\
& & Manangih.
\end{tabular}

2. Kesetiakawanan di- Kawan Nan Setia, tuntun walaupun da- Tupai jo Limbek, Tulam kondisi yang pai jo Limbek. terbatas

3 Bertindak harus dip- Kucing Jo Paladang, ikirlan dan hati-hati

4 Kejujuran akan bera- Anak Nan Jujur, dan khir dengan kebaha- Anak Mudo, Si Aik giaan Dari Padang Panjang, dan Limau Hanyuik,
5 Kesombongan tidak Rumah Raksasa, baik dalam kehidu- Kisah Boruak, dan pan
Unggeh si Ninik,
$6 \quad$ Ketangkasan Kuciang Jo Harimau makhluk berbeda dan terbatas
7 Perhatikan nasihat orang tua jika mau selamat
Dek Ndak Mandon- gaan Kecek Urang Tuo dan Harimau Jo Anaknyo

8 Pikiran kreatif diper- Kania Makan Antilukan dalam hidup mun dan Binatang Kancia

9 Pituah yang tidak di- Baa Ayam Sampai jaga baik bisa mem- Kini Dek Mangakeh bawa permusuhan

10 Berteman hendaklah Pipik Jo Onggang dicari sesuai dengan kondisi dari masing-masing

11 Orang Minangkabau Panyabab Urang hidup berbaur den- Minangkabau Magan di luar budayan- makai Sistem Matriya lineal

Pesan yang disampaikan oleh cerita ada yang sama antara satu cerita dengan cerita lain. Terjadinya persamaan pesan dalam cerita sesuai dengan tujuan dan fungsi dari cerita lisan yaitu menyampaikan nilai dan edukasi secara umum kepada masyarakat (Jirata, 2013). Persamaan dan perbedaan dalam mengemas pesan, nilai, atau edukasi dalam cerita mengakibat terjadi variasi. Variasi itu bukan hanya pada cerita yang berbeda tetapi juga terjadi dalam cerita yang sama. Variasi itu suatu yang logis terjadi pada tradisi lisan karena yang diperhatikan dalam tradisi ini adalah nilai dan pesan utama (Eklund, 2017). Nilai dan pesan 
utama cerita dipertahankan walaupun ada bagian cerita yang ditambah, dikurangi, diperpanjang, dipendekkan, atau sengaja dihilangkan. Namun, cerita masih memperlihat adanya nilai dan pesan tersebut (Swenney, 1980, Lord, 1991, Rubin, 1995).

Demikian juga dengan nilai-nilai kemanusiaan dalam cerita anak tidak bervariasi, dominan unsur didaktik, dan bersifat monoton (Sastriyani, 2006: 10). Nilai-nilai kemanusiaan yang sering muncul dan hampir muncul di berbagai daerah yaitu mengajak supaya menghormati orang tua. Nilai itu disampaikan lewat tokoh anak laki-laki dan maupun tokoh anak perempuan. Jika tokoh anak tidak menghormati ibu maka berakibat fatal bagi kelangsungan hidup sang anak seperti menjadi batu, terbenam dalam lumpur, berubah menjadi benda mati atau makhluk lain yang tidak diinginkan. Cerita seperti pesan di atas pada cerita anak di Minangkabau dominan ditemukan walaupun berbeda-beda. Perbedaan ini disebabkan karena daerah adat yang berlainan. Daerah adat di Minangkabau dibedakan atas 1) daerah darek yang disebut dengan luhak, 2) daerah rantau, dan 3) daerah pasisia (BendaBeckmann, 1979, Naim, 1985, Azra, 2003). Semua daerah adat ini mempunyai cerita yang mengedukasi supaya anak bersikap sopan dan hormat kepada ibu. Ada 9 cerita dengan pesan yang sama yaitu dari cerita nomor 1 sampai nomor 10. Cerita itu adalah cerita Si Buncik, Sapan Mandidiah, Bancah Birunguik, Batu Bangkai, Batu Balacan, Awang Tingkuluak, Aia Manggaloggak, Boncah Tangkuluak, Tobek si Ombie, dan cerita Batu Manangih (Gayatri, 2015 dan 2020).

Cerita lisan tidak hanya berfungsi sebagai alat penghibur, pengisi waktu senggang, dan penyalur perasaan penutur dan pendengarnya. Cerita lisan juga mencerminkan sikap, pandangan dan angan-angan kelompok, alat pen- didik anak-anak, alat pengesahan pranata dan lembaga kebudayaan serta pemeliharaan norma masyarakat (Danadjaja, 1984: Djamaris, 1993: Endraswara, 2013: Fachrudin, 1981: 1). Cerita anak Minangkabau salah satu bentuk folklor sama-sama memperlihatkan fungsi selain pendidikan juga mencerminkan sikap, atau mengesahkan pranata sosial, dan lainlain.

Cerita anak yang telah dianalisis ini memberikan pesan dominan agar hormat kepada ibu yaitu sebanyak 10 cerita. Pesan ini memberikan pendidikan, terutama kepada anak, ibu, dan lingkungan untuk membentuk karakter seorang anak. Masyarakat Minangkabau berdasarkan garis keturunan matrilineal menempatkan ibu sebagai tokoh sentral dalam rangka menanamkan karakter seorang anak. Jika edukasi yang diberikan ibu tidak benar maka kewenangan dan posisi dari sistem matrilineal untuk membesarkan, mengarahkan, dan membimbing anaknya menjadi kandas. Oleh sebab itu, cerita berfungsi juga untuk mengingatkan seorang ibu untuk mendidik anaknya. Ibu yang tidak baik dan tidak mampu memberikan pendidikan kepada anak membuat anak menjadi pribadi yang tidak disukai oleh lingkungan, keluarga, dan Allah. Salah satu kegagalan dari ibu adalah anak yang tidak bersikap baik kepada ibunya.

Cerita anak Minangkabau dengan tokoh binatang diantaranya, cerita Si Kancil dengan Tukang Kebun, Kacil dengan Harimau, Anjing dengan Kuncing dan lain-lain. Cerita dengan tokoh binatang dianggap cerita yang paling tua. Hal ini mengingat binatang dianggap makhluk yang sejak awal banyak bergaul dengan manusia (Bunanta, 1998; Sarumpaet, 2010: 20). Melalui tokoh binatang untuk menyampaikan unsur didaktik dan moral serta diibaratkan bertingkah laku seperti manusia dan menyampaikan pesan kepada pendengar- 
nya (Nurgiyantoro, 1998). Cerita dengan tokoh binatang termasuk kategori dongeng. Dongeng adalah cerita khusus tentang manusia dan binatang yang dianggap benar terjadi dengan bersifat hiburan walaupun ada mengandung kebenaran dan pesan moral (Ahimya-Putra, 2003).

Dari kumpulan cerita itu ditemukan cerita tergolong fabel diantaranya 1) Tupai jo Limbek, 2) Kuciang jo Paladang, 3) Kuciang Jo Harimau, 4) Harimau Jo Anaknyo, 5) Kisah Boruak, 6) Kancia Makan Antimun, 7) Binatang Kancia, 8) Pipik Jo Onggang, dan 9) Unggeh si Ninik, 10) Kawan Nan Setia (Gayatri, dkk, 2015). Cerita dengan tokoh binatang ini ada yang menyampaikan pesan dan nasihat, tetapi ada juga cerita tersebut bersifat hiburan dan mengandung lelucon. Cerita yang menyampaikan nilai-nilai kemanusiaan adalah cerita 1) Tupai jo Limbek, 2) Kuciang jo Paladang, 3) Kuciang Jo Harimau, dan 4) Harimau Jo Anaknyo, 5) Kawan Nan Setia, 6) Tupai Jo Limbek dan lain-lain.

Nilai kemanusiaan dari cerita dengan tokoh binatang dan tokoh manusia yaitu nilai kejujuran. Nilai kejujuran pada cerita ditemukan sebanyak 4 cerita walaupun ada juga pada cerita yang lain.

Kejujuran merupakan inti dari pendidikan karakter yang sedang digalakkan oleh pemerintah. Kejujuran pondasi utama untuk bertahannya nilai-nilai kebenaran karena jujur sangat identik dengan kebenaran. Dalam ajaran agama Islam, kejujuran merupakan salah satu sifat dari Nabi Muhamad (Amin, 2017). Kejujuran adalah salah satu karakter bangsa Indonesia yang tercermin dalam Pancasila maka dimasukkan ke dalam nilai moral dan dasar dari segala prilaku terpuji lainnya. Karakter jujur sesuatu yang penting agar dimiliki oleh semua generasi muda dan ke depan agar tercipta generasi berkualitas. Dengan adanya karakter kejujuran pada generasi akan datang maka di dalam dirinya tidak akan mau merugikan orang lain.

Cerita yang menyampaikan pesan kejujuran yaitu "cerita Anak Mudo, Limau Anyuik, Anan Nan Jujur, dan Si Aik Dari Padang Panjang. Kejujuran dari dua cerita yaitu cerita Anak Mudo dan Limau Anyuik sama-sama mengisahkan seorang pemuda mencari orang yang mempunyai buah yang telah dimakannya. Buah dimakan terlebih dahulu karena pemuda itu sangat haus. Buah tersebut tidak diketahui siapa yang mempunyai dan ditemukan hanyut di sungai. Oleh sebab itu, tanpa pikir panjang dimakan buah tersebut. Setelah buah habis dimakan, kemudian timbul pikiran pemilik buah yang telah dimakan. Buah telah habis tetapi belum minta izin kepada yang mempunyainya. Oleh sebab itu, pemuda berusaha mencari orang yang mempunyai buah dengan menelusuri tepi sungai sampai ditemuinya batang buah yang telah dimakan.

Batang buah itu tumbuh di sebuah rumah. Lalu dipanggilnya orang di dalam rumah dan diceritakan kejadian yang dilakukan. Pemuda itu minta restu supaya direlakan buah yang telah dimakannya. Orang yang mempunyai buah itu merelakan buah yang telah dimakan, tetapi harus mengawini anak perempuannya. Anak perempuannya dinyatakan anak yang cacat, buta, tuli, serta tidak mempunyai tangan dan kaki.

Dengan berat hati sang pemuda menerima pinangan bapak yang mempunyai buah. Setelah pemuda menyatakan bersedia menerima pinangan bapak itu, maka keluar seorang anak gadis cantik dan tidak ada tubuh yang cacat. Bapak itu mengibaratkan anaknya tidak mempunyai mata dan anggota tubuh karena tidak pernah melihat dan melakukan perbuatan berdosa. Anak gadis itu juga berkepribadian baik dan sopan. Akhir cerita dikisahkan keluarga pemuda itu menjadi keluarga yang sejahtera. 
Demikian juga pada cerita “Anak Nan Jujur" masih menekankan nilai kejujuran. Kejujuran dilakukan dalam segala aktifitas ditekannkan dan harus ditanamkan sejak dari kecil. Cerita ini memperkuat pentingnya kejujuran walaupun sedang mengancam nyawa, tapi kejujuran terus dilakukan.

Cerita “Anak Nan Jujur" mengkisahkan seorang anak berjalan di hutan seorang diri. Di hutan, dia bertemu dengan tiga orang penyamun yang galak. Penyamun itu akan mengambil uangnya. Sebelumnya, penyamun menanyakan apakah anak kecil itu mempunyai uang. Dengan jujur anak kecil itu menjawab, bahwa dia mempunyai uang yang diletakkan di bawah ketiaknya. Pernyataan itu diucapkannya sebanyak tiga kali dengan tidak merasa gemetar, walaupun kondisi jiwanya terancam yang sedang berada di tengah hutan. Kegentingan kondisi itu terlihat dari kutipan cerita di bawah ini.

Tibo lah inyo di dalam rimbo, basoroboklah inyo jo 3 urang.

"Hai anak mudo kama ang?", kecek panyamun itu. Ndak dijawabnyo do. "Lai ado ang bapiti?, keceknyo panyamun iko baliak.

"Lai Pak, jawabnyo. "Dimaa ang lotakan?"

"Di bawah katiak Pak," jawab anak iko tadi.

Dek lah tigo kali dijawabnyo takah itu, tantu berang urang panyamun itu.

"Maa ang latak-an di bawah katiak den?, kecek urang panyamun itu.

"Iko piti di bawah katiak den ang," keceknyo baliak

"Ondeh jujurnyo anak iko ndak tantu dek inyo ka mati do," kecek salah surang panyamun. Iko anak ketek baru lah pandai mangecek jujur." (Gayatri, 2015: 65).
(Tibalah dia di dalam rimba, bertemulah dia dengan 3 orang.

"Hai anak muda kemana kamu?", kata penyamun itu. Tidak dijawabnya. "Apa kamu punya uang?, tanya penyamun itu kembali.

"Ada Pak, jawabnya. "Dimana kamu letakkan?"

"Di bawah ketiak Pak," jawab anak itu tadi.

Karena sudah tiga kali dijawabnya seperti itu, tentu marah orang penyamun itu.

"Mana kamu letakkan, di bawah ketiak saya?, kata orang penyamun itu.

"Ini uang di bawah ketiak saya," katanya kembali

"Aduh jujurnya anak ini, tidak tahu dia akan mati," kata salah seorang penyamun. Ini adalah anak kecil yang pandai berkata jujur.")

Nilai kejujuran yang diperlihatkan pada cerita "Si Aik dari Padang Panjang" mengkisahkan anak laki-laki yang bernama si Aik. Anak ini bersifat jujur. Terbukti waktu dia menemukan dan mengembalikan anting kepunyaan dari anak kepala penjara. Anting didapatkan si Aik waktu dia mengambil sampah di rumah kepala penjara. Anak perempuan kepala penjara mengetahui antingnya hilang dan dia sangat sedih karena anting itu dibuat di Belanda.

Waktu si Aik menemukan anting dan memberikan kepada istri kepala penjara meskipun tidak ada orang melihat dia menemukan anting itu. Melihat kejujuran si Aik, maka keluarga kepala penjara menyuruh tidur di rumahnya. Selama ini si Aik tidur di penjara. Pada akhir cerita, si Aik dinikahkan dengan anak kepala penjara. Di bawah ini, dikutip bagian yang menceritakan kejujuran dari si Aik. 
Malang tibo dek si Risani jatuah subangnyo. Subangnyo dari intan, dibuek di Balando. Manangih-nangihnyo dek barangnyo hilang. Ndak baraa lamo kudian, pulang ayahnyo. Kecek ayahnyo, "ndak baa hilang do". Bisuaknyo basuo ma." "Tapi bueknyo kan ndak di siko do Yah, kan dibuek di Balando," kecek si Rasani. Ndak baraa lamo, si Aik pai ka rumah urang Balando tu ndak maambiak sarok di rumah Risani. Kudian, dibaonyo ka Muaro. Inyo dek kamanyampak-an sarok ka Muaro, nampak dek inyo subang. Subang tu diambiaknyo, lalu pai inyo ka rumah si Risani. Dikecek-an disinan.

"Ambo dapek subang Bu, ikonyo ah. Lai Ibu yang punyo iko?"

Nan kecek Ibu Risani, "Iyo ambo nan punyo maa." Lalu diagiahanlah dek si Aik ka inyo (Gayatri, 2015: 32).

(Malang tiba oleh si Risani jatuh antingnya. Antingnya dari intan, dibuat di Belanda. Menangis-nangis dia karena antingnya hilang. Tidak berapa lama kemudian, pulang ayahnya. Kata ayahnya, "tidak apaapa hilang". Besok akan ketemu kembali." "Tapi antingnya tidak dibuat di sini. Ayah, anting ini dibuat di Belanda," kata si Rasani.

Tidak berapa lama, si Aik pergi ke rumah orang Belanda itu hendak mengambil sampah di rumah Risani. Kemudian, dibawanya ke Muaro. Karena dia akan membuang sampah ke Muaro, tampak olehnya anting. Anting itu diambilnya, lalu pergi dia ke rumah si Risani. Dikatakan di situ.

"Hamba dapat anting Bu, ini. Apa Ibu yang punya ini?"

Kata Ibu Risani, "Iya hamba yang punya." Lalu dikasihkan oleh si Aik ke ibunya).
Cerita di atas menyampaikan pesan bahwa kejujuran sangat penting dan harus dijaga dalam kondisi apapun. Setiap kejujuran yang dilakukan memperoleh balasan kebahagiaan.

Ketiga cerita di atas menyampaikan nilai kejujuran dan ketiga tokoh tersebut di akhir cerita mendapatkan kebahagiaan. Kebahagiaan diperlihatkan dengan menemukan jodoh istri cantik, baik, sholehah, atau perempuan dari segi status sosial lebih baik dari tokoh. Pernikahan terjadi mirip pada cerita Bawang Merah dan Bawang Putih. Tokoh Bawang Putih hidup miskin sehingga selalu direndahkan oleh Bawang Merah. Namun, berkat kerendahan dan kesederhanaan sikap Bawang Putih maka dia dipinang oleh pangeran. Pernikahan yang di luar perkiraan semua orang (Bunanta, 1998).

Selain nilai kejujuran, nilai kesetiakawanan juga ditemui dalam cerita yang dianalisis. Kesetiakawanan itu diperlihatkan juga oleh tokoh binatang yaitu pada cerita Tupai jo Limbek dan cerita Kawan Nan Setia. Kedua cerita ini sama-sama mengisahkan 2 binatang bertubuh kecil dengan tempat hidup yang berbeda. Tokoh cerita Tupai jo Limbek yaitu tupai yang hidup di pohon sedangkan limbek hidup di air. Limbek adalah sejenis ikan lele. Kedua binatang ini dikisahkan bersahabat. Ikatan sahabat ini saling membantu walaupun dalam kondisi anggota tubuh yang tidak memungkinkan.

Suatu hari tupai sakit sampai matanya tidak bisa melihat. Waktu itu ikan lele bermimpi. Dalam mimpinya dikatakan bahwa obat sakit mata tupai adalah telur ayam. Pergilah ikan lele mencari telur ayam dengan susah payah karena tidak mempunyai tangan. Dengan keterbatasan fisik itu ikan lele tetap gigih berusaha membantu temannya. Akhirnya, ikan lele mendapatkan telur dan dilemparkannya ke tupai sehingga tupai sembuh dan bisa melihat kembali. Rentetan peristiwa yang sama 
juga terjadi pada cerita Kawan Nan Setia. Perbedaan hanya terjadi pada tokohnya yaitu macik (tikus) dengan ikan ruan (ikan gabus).

Pesan yang disampaikan dari fabel ini adalah persahabat dan saling tolong-menolong dalam kondisi apapun. Keterbatasan fisik tidak menjadikan alasan untuk tidak menolong sahabat. Terbukti ikan lele yang tidak mempunyai tangan, tetapi tetap membantu sahabatnya.

Berbeda kenyataannya pada cerita $\mathrm{Ku}$ ciang jo Palandang, kesetiaan, dan kepatuhan dari kucing kepada tuannya justru dibalas dan menjadi petaka bagi dirinya. Cerita Kuciang jo Paladang mengisahkan kehidupan seorang petani yang mempunyai seorang anak bayi dan seekor kucing. Kuncing itu sangat setia dan patuh kepada tuannya. Suatu hari, petani pergi ke ladang bersama istrinya sehingga anaknya dititip dan dijaga oleh kuncing. Kuncing itu patuh dengan perintah tuannya dan selalu menjaga anaknya sampai kucing tidak mau tidur. Waktu itu, ular masuk ke dalam rumah dan akan menggigit bayi tuannya. Kuncing langsung menghalangi sehingga terjadi perkelahian antara kucing dengan ular. Akhirnya, ular mati dengan meninggalkan bekas darah di halaman rumah. Melihat halaman rumah berdarah-darah maka petani yang baru datang dari kebun marah-marah. Petani menduga anaknya sudah dimakan oleh kucing. Dia menggambil kayu, langsung dipukulnya kucing sehingga mati. Kemudian, petani masuk ke dalam rumahnya. Ternyata anaknya masih tidur dan terlihat ada ular yang berdarah. Waktu itu, timbul penyesalannya melihat kucing yang telah mati. Kuncing yang sangat setia dan patuh pada dirinya, tetapi telah mati di tangannya. Akhirnya, timbul penyesalan melihat kucing yang telah mati padahal sudah menjaga anaknya.
Dari cerita ini, dapat ditarik pelajaran dan pesan supaya tidak cepat menaruh curiga serta emosional melihat suatu kejadian. Selidiki dan amati terlebih dahulu agar tidak timbul penyesalan, seperti yang dilakukan oleh petani kepada kucing kesayangannya. Cerita ini memberikan nasehat supaya perbuatan dan tindakan harus dilakukan dengan cermat dan hatihati.

Fungsi dari sastra lisan juga digunakan untuk mengkritik secara tidak langsung fenomena yang terjadi di masyarakat. Jika tidak mungkin menyampaikan sesuatu hal secara langsung maka disampaikan dengan cara sindiran melalui cerita (Finnegan, 1992: Endraswara, 2013). Banyak terjadi di masyarakat seseorang yang melakukan tindakan secara gegabah dan emosional. Mungkin saja cerita ini memberikan sindiran kepada manusia. Binatang seperti kucing bisa bersikap setia dan patuh pada tuannya. Justru manusia makhluk sempurna yang diberi perasaan dan pikiran malahan lebih beringas dari pada binatang. Terlihat ketidakmampuan manusia mengendalikan emosinya. Jadi cerita ini mungkin juga merupakan kritikan yang bersifat sinisme terhadap manusia.

\section{KESIMPULAN}

Artikel ini berusaha mengungkapkan nilai-nilai kemanusiaan yang ditemui dalam cerita anak Minangkabau meskipun cerita ini sudah jarang disampaikan kepada anak-anak. Padahal cerita anak mengandung pesan dan nilai-nilai yang masih relevan saat ini. Nilai yang ditemukan dari cerita ini bisa juga disampaikan untuk anak-anak di luar Minangkabau. Cerita anak sesuai dengan fungsinya lebih mengutamakan pendidikan demikian juga dengan cerita anak Minangkabau banyak memberikan pendidikan bersifat umum kepada anak-anak. 
Nilai-nilai kemanusiaan yang ditemui dalam cerita anak Minangkabau adalah mengajak anak bersikap hormat kepada orang terutama ibu, kejujuran harus dilakukan dalam segala kehidupan dan dilaksanakan, kesetiakawanan harus diperlihatkan walaupun dalam kondisi yang sulit, dan manusia bertindak jangan gegabah karena dapat menghilangkan rasionalitasnya. Jadi nilai yang ditemukan dalam cerita anak di Minangkabau disarankan juga disampaikan kepada anak-anak di luar Minangkabau karena nilai tersebut bersifat universal dan netral.

\section{UCAPAN TERIMA KASIH}

Artikel ini merupakan salah satu output dari hibah penelitian di Universitas Andalas. Oleh karena itu, tim peneliti mengucapkan terima kasih kepada Rektor, Ketua Lembaga Penelitian dan Pengabdian, serta staf Universitas Andalas atas bantuan moril dan materilnya dalam melaksanakan penelitian ini. Selanjutnya, diucapkan terima kasih kepada semua informan dan pihak-pihak yang telah membantu kelancaran penelitian ini semoga menjadi amal ibadah bagi Bapal/ibu/ dan saudara. Aamiin.

\section{DAFTAR PUSTAKA}

Ahimya-Putra, H. (2003). "Dari Antropologi Budaya ke Sastra, dan Sebaliknya". Dalam Sastra Interdisipliner Menyandingkan Sastra dan Disiplin Ilmu Sosial, ed. Muh. Arif Rokhman, dkk. Yogyakarta: Qalam.

Almerico, G. (2004). "Building character through literacy with children's literature". Dalam Research in Higher Education Journal Volume 26 Oktober, 2014, pp. 1-13. http://www.aabri.com/copyright.html.
Amin, M. (2017). "Peranan Guru dalam Menanamkan Nilai Kejujuran Pada Lembaga Pendidikan". Tadbir Jurnal Studi Menajemen Pendidikan. Vol. 1 Nomor. 1. Tahun 2017. Hal. 105- 124.

Anwar, K. (1995). Beberapa Aspek Sosio-Keltural Masalah Bahasa. Yogyakarta. Gadjah Mada University Press.

Apriliya S, H, dan Umul K (2020). "Pagi Sampai Malam Hari: Representasi Latar Waktu Dalam Cerita Anak Indonesia". Jurnal Diksi Vol. 28, No. 2, September 2020. Hal. 155-161 https://journal.uny. ac.id/index.php/diksi/article/view/33354. Diakses tanggal 11 Agus 2021.

Azra, A. (2003). Surau Pendidikan Islam Tradisional dalam Transisi dan Modernisasi. Terjemahan oleh Iding Rasyidin. Jakarta. Logos Wacana Ilmu.

Ben-Amos, D. (1984). "The Seven Strands of Tradition: Varieties in Its Meaning in American Folklore Studies". Journal of Folklore Research, Vol. 21, No. 2/3, Culture, Tradition, Identity Conference, March 26-28, 1984 (May-Dec., 1984), pp. 97-131. https:// www.jstor.org/stable/3814548. Diakses pada 8 Desember 2018.

Benda-Beckmann, F. (1979). Property in Social Continuity: Continuity and Change in the Maintenance of Property Relationships through Time in Minangkabau, West Sumatra. Leiden: The Hague - Martinus Nijhoff

Benda-Beckmann, F. (2012). "Islamic Law in a Plural Context: 1he Struggle over Inheritance Law in Colonial West Sumatra". Journal of The Economic and Social History of the Orient (2012), pp. 771-793.

Blank, J. (2009). "Folklore and the Internet: Vernacular Expression in a Digital World". Western Folklore, Vol. 70, No. 3/4 (Summer/Fall 2011), pp. 376-377. 
Blank, J. (2009). Folklore and The Internet: Vernacular Expression In a Digital World. Logan Utah: Utah State University Press.

Bunanta, M. (1998). Problematika Penulisan Cerita Rakyat Untuk Anak di Indonesia. Jakarta: Balai Pustaka.

Chaniago, H. (2010). 101 Orang Minang di Pentas Sejarah. Padang: Yayasan Citra Budaya Indonesia.

Danadjaja, J. (1984). Folklor Indonesia Ilmu Gosip, Dongeng, dan lain-lain. Jakarta: Grafiti Medika Pers

Djamaris, E. (1993). Nilai Budaya Sastra Nusantara: Nilai Budaya dalam Kaba Meget Manadin. Jakarta: Pusat Pembinaan dan Pengembangan Bahasa.

Eklund, E. (2017). "Memory and Enshrining Writing: Rethinking the Ethnocentrism Imbedded in Written vs. Oral Traditions". Jurnal Arizona Antropology No. 28, pp. 76-87.

Endraswara, S. (2013). Pendidikan Karakter dalam Folklor Konsep, Bentuk, dan Model. Yogyakarta: Pustaka Rumah Suluh.

Finnegan, R. (1992). Oral Traditions and The Verbal Arts A Guide to R e s e a r c $h$ Practices. London and New York. Routledge.

Fitrah, Y, (2012). "Pembelajaran Sastra Anak: Materi Ajar Sederhana Menuju Pembentukan Budi Pekerti dan Akhlak Anak", pp. 87-92. Artikel disampaikan pada Konferensi Internasional Kesusastraan XXII UNY-HISKI, 2012

Fitriana, I. (2013). "Penerjemahan Karya Sastra Anak". Jurnal Diglossia Vol. 4 No. 2 Hal. 1-12. Diunduh pada tanggal 6 Desember 2020 dari http://www.journal. unipdu.ac.id/index.php/diglosia/article/ view/286.
Gayatri, S. (2015). Kumpulan Cerita Anak Minangkabau. Sastra MinangkabauFakultas Ilmu Budaya Universitas Andalas Gayatri, S. (2020). "Carito Anak Minangkabau Variasi Teks Dan Sistem Pewarisannya: Pendekatan Kelisanan". Yogyakarta. Disertasi. Pascasarjana Universitas Gajah Mada.

Gunawan, R. (2008). "Kearifan Lokal dalam Tradisi Lisan dan Karya Sastra". Makalah Kongres Bahasa 28-31 Oktober 2008, Jakarta.

Gwyndaf, R. (1993). "Folk Legends in Welsh Oral Tradition: Principles of Research, Continuity And Function" Finscealta Agus Litriocht: Paipeir a cuireadh I lathair ag an Siompoisiam NordachCeiltech/Legends and Fiction: Papers Presented at the Nordic-Celtic Legend Symposium (1992/1993), pp. 215-240 Diunduh pada tanggal 8 Desember 2019 02:06 UTC URL: https://www.jstor.org/ stable/20522408

Hadler, J. (2010). Sengketa Tiada Putus Matriarkat, Reformisme Islam, dan Kolonialisme di Minangkabau. Terjemahan oleh Samsudin Berlian. Jakarta: Freedom Institute.

Hartono, R. (2017). Pengantar Ilmu Menerjemah (Teori Dan Praktek Penerjemahan). Semarang: Green Vilage

Hasanuddin, W.S, (2006). "Warisan Budaya Tak Benda Ungkapan Tradisional Minangkabau: Kearifan Lokal Masyarakat Tentang Tunjuk Ajar dan Nilai-Nilai Budaya". Jurnal Humanus, Vol. XV No. 2. Oktober 2006, hal 131-141.

Jirata, T. (2013). "Children and Oral Tradition Among the Guji-Oromo in Southern Ethiopia". Thesis for the degree of Philosophiae Doctor. Norwegian University 
of Science and Technology Faculty of Social Sciences and Technology Management Norwegian Centre for Child Research.

Kechik, T. (2013). "Cerita Rakyat Sebagai Pendidikan ke Arah Pembentukan Karakter Pemimpin Politik" Dalam Folklor dan Folklife Dalam Kehidupan Dunia Modern Kesatuan dan Keberagaman. (ed) Endraswara, dkk. Yogjakarta. Ombak.

Khoiriyah, R. (2015). "Pemberian Relaksasi Melalui Dongeng Untuk Menurunkan Stress dan Gangguan Tidur Pada Anak Panti Asuhan". Tesis Program Magister Psikologi Profesi Fakultas Psikologi Universitas Gajah Mada.

Lord, A. (1991). The Singer of Tales. Ithaca And London: Cornell University Press

Mursini, (2011). Apresiasi \& Pembelajaran Sastra Anak-Anak. Bandung: Citapustaka Media Perintis.

Musfiroh, T. (2008). Memilih, Menyusun, dan Menyajikan Cerita untuk Anak Usia Di$n i$. Yogyakarta. Tiara Wacana.

Naim, M. (1985). Merantau Pola Migrasi Suku Minangkabau. Yogyakarta. Gadjah Mada University Press.

Nurgiyantoro, B. (1998). Teori Pengkajian Fiksi. Yogyakarta: Gajah Mada University Press.

Nurgiyantoro, B. (2010). Sastra Anak Pengantar Pemahanan Dunia Anak. (Cetakan ke-2). Yogjakarta: Gadjah Mada University Press.

Ong. W. (2013). Kelisanan dan Keberaksaraan. Terjemahan oleh Rika Iffati. Yogjakarta: Gading Publishing.

Sarumpaet, R. (2010). Pedoman Penelitian Sastra Anak. Jakarta: Yayasan Pustaka Obor Indonesia.
Sastriyani, S. (2006). Kajian Sastra Anak Perancis. Yogyakarta: Bigraf Publishing.

Sikana, M. (2007). Teras Sastera Melayu Tradisional. Singapura. Pustaka Karya.

Sugihastuti, (2013). Tentang Cerita Anak. (Cetakan ke-3) Yogyakarta: Pustaka Pelajar.

Sukatman, (2009). Butir-Butir Tradisi Lisan Indonesia Pengantar Teori dan Pembelajarannya. Yogyakarta: LaksBang PRESSindo.

Sunarti, S. (2013). Kelisanan dan Keberaksaraan dalam Surat Kabar Terbitan Awal di Minangkabau (1859-1940-an). Jakarta: Gramedia.

Sweeney, A. (1980). Authors and Audiences in Traditional Malay Literature. Berkeley: University of Colifornia Press.

Rahman, F. (2010). "Sastra Anak Dalam Persimpangan" Jurnal Lensa Budaya Vol 5 No 1, April 2010, pp. 26-35.

Ratna, N. (2014). Peranan Karya Sastra, Seni, dan Budaya Dalam Pendidikan Karakter. Yogyakarta: Pustaka Pelajar.

Rubin, D. (1995). Memory In Oral Traditions the Cognitive Psychology of Epic, Ballads, and Counting-Out Rhymes. New York: Oxford University Press

Tucker, E. (2008). Children's Folklore: A Handbook. Westport, London: Greenwood Press.

Tulius, J. (2013). "Family Stories: Oral Tradition, Memories of The Past, And Contemporary Conflicts Over Land in Mentawai-Indonesia". Wacana, Journal of The Humanities of Indonesia. Wacana, Vol. 15 No. 1 (2013).

Udasmoro, W. (2012). Sastra Anak dan Pendidikan Karakter. Yogyakarta: Program Studi Sastra Perancis Fak. Ilmu Budaya Universitas Gajah Mada. 
Wilson D, D. (2014). "A Study on Oral Tradition as a Communication Tool". International Journal of Social Sciences. Volume-2, Issue-3) June 2014 pp. 7-10. Diunduh http://www.ijss.publicationsupport.com/docs/paper/Volume-2/Issue_3/ IJSSV2I1-116.pdf

Widyastuti, S. "Resensi Buku Menimbang Sastra Anak". Jurnal Diksi Vol. 13, No. 1 Hal. 104-105. Diunduh pada tanggal 12 Agus 2021. https://journal.uny.ac.id/index.php/diksi/article/view/6447.
WS, H. (2006). "Warisan Budaya Takbenda Ungkapan Tradisional Minangkabau: Kearifan Lokal Masyarakat tentang Tunjuk Ajar dan Nilai-Nilai Budaya". dalam jurnal Humanus, Vol. XV No. 2. Oktober 2006. Hal 131-141. Printed ISSN 14108062. Online ISSN 2928-3936 Padang: FPBS Universitas Negeri Padang.

Zakaria, N., \& Che R., (2013). "Cerita Rakyat sebagai Penerapan Nilai-Nilai Murni Dalam Kalangan Kanak-Kanak”. Dalam Folklor dan Folklife Dalam Kehidupan Dunia Modern Kesatuan dan Keberagaman, ed. Endraswara, dkk Yogyakarta. Ombak. 